\title{
Práticas de percepção da fertilidade entre mulheres jovens
}

\author{
Bruna Klöppel' (iD 0000-0002-7985-4935 \\ Fabíola Rohden' (iD 0000-0003-3355-6841 \\ 'Universidade Federal do Rio Grande do Sul, Porto Alegre, RS, Brasil. \\ 915910-970-ppgifch@ufrgs.br
}

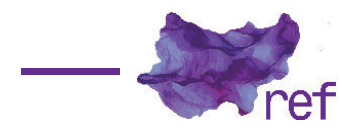

Resumo: Neste artigo temos como objetivo caracterizar uma configuração em torno da percepção da fertilidade e descrever sua articulação ao aparato de gênero e à biomedicalização. Com uma abordagem etnográfica, tomamos como ponto de partida um grupo no Facebook sobre percepção da fertilidade e realizamos entrevistas semiestruturadas com seis de suas porta-vozes. Além disso, analisamos Iivros e sítios que nos foram indicados nessas entrevistas e fizemos observação participante em um curso presencial ministrado por uma das interlocutoras. Concluímos que concomitante a projetos coletivos de empoderamento de corpos e subjetividades com ciclos menstruais, há responsabilização individual pela saúde e pelo autoaprimoramento. Ademais, reforça-se a substancialização do binarismo sexual com a produção de uma "natureza hormonal", ainda que seja mais associada à saúde que ao gênero. Palavras-chave: Percepção da fertilidade; Biomedicalização; Gênero; Empoderamento; Hormônios.

\section{Fertility Awareness Practices Among Young Women}

Abstract: The article aims to characterize fertility awareness and describe its articulation with the gender apparatus and biomedicalization. With an ethnographic approach, we took a group on Facebook as a starting point and conducted semi-structured interviews with six of its spokespersons. In addition, we analyzed books and sites recommended in these interviews and made participant observation in a face-to-face course given by one of the interlocutors. We conclude that fertility awareness practices are related to collective projects for empowering bodies and subjectivities with menstrual cycles and at the same time to individual responsibilisation for health and self-improvement. Furthermore, it reinforces the substantialization of sexual binarism with the production of a "hormonal nature", although it is linked to health instead of gender.

Keywords: Fertility Awareness; Biomedicalization; Gender; Empowerment; Hormones.

\section{Reconfigurando hormônios, naturezas e gêneros}

Eu disse: "O que eu quero é ovular, porque reconheço isso como sinal de saúde, dentro dos meus estudos". E o médico perguntou: "Mas você quer engravidar?". E eu: "Não, não quero, mas quero ovular, e já faz três meses que não ovulo". Ele ficou insistindo que eu queria ovular porque queria engravidar. "Mas você tem parceiro? Então você quer engravidar." E eu, então, disse: "Vamos cuidar do que é importante para o processo de ovular, que é importante pra mim. Quero ovular, mas não quero engravidar". E ele insistindo. Até que eu: "Mas você pode reconhecer se meu corpo está bem, dentro da sua competência médica?". Era isso que eu precisava. Eu queria saber sobre minha saúde, do meu sistema reprodutor, porque está relacionada à saúde total. É metonímia da saúde total" (Talita, 08/08/2016).

Este trecho narra o diálogo entre uma jovem psicóloga de 23 anos e um médico endocrinologista e foi produzido no contexto de uma entrevista. Quando conversamos pela primeira vez com Talita, em agosto de 2016, fazia um ano que havia interrompido o consumo de hormônios contraceptivos, que começou a utilizar aos 17 anos. Substituiu esse método 
anticoncepcional pelas práticas de percepção da fertilidade por ter necessidade de se "conhecer fértil", já que se sentia "especialmente estéril". Descrevia tal esterilidade como uma "falta de desejos e movimentos criativos" e "medo da saúde mesmo quando os exames iam bem", o que entendia como efeito do uso dos hormônios anticoncepcionais. Com a interrupção do uso dos hormônios, Talita contou ter experienciado uma mudança grande, na qual o "desejo de vida, para além do desejo sexual, aumentou bastante".

Apesar de constatar essa mudança positiva, sentia-se ainda insatisfeita por não conseguir confirmar a ocorrência de nenhuma ovulação até aquele momento, o que deixava Talita preocupada. Dentre outras ações que tomou por conta dessa preocupação, decidiu buscar um endocrinologista, "o médico dos hormônios", que a levou ao encontro relatado acima. Frustrada por "não conseguir ovular", foi apenas em novembro de 2016 que Talita enviou mensagens a suas amigas comemorando o fato de ter finalmente menstruado, fruto de uma ovulação que havia confirmado.

Mas afinal, como Talita chegou à conclusão de que não estava ovulando e por que desejava ovular? Por que Talita acreditava que, deixando de tomar contraceptivos hormonais, aumentaria seu "desejo de vida"? Por que enfrentou seu médico para defender uma vinculação entre ovulação, hormônios e saúde, recusando uma associação direta entre ovulação e gravidez? Essas são algumas das questões que responderemos ao longo deste artigo, ao mostrar como corpos e subjetividades específicos são produzidos enquanto efeitos de novas práticas relacionadas à percepção da fertilidade.

A entrevista de Talita, de forma exemplar, sintetiza o objeto em análise neste artigo. Trata-se de uma nova configuração relativa a práticas da percepção da fertilidade que tem se destacado em certos segmentos de mulheres jovens no Brasil e se articula, sobretudo, via internet e redes sociais. A pesquisa que embasa este trabalho, portanto, teve como foco um grupo dedicado ao tema no Facebook por meio da análise de suas publicações e de outros sítios e documentos, da realização de entrevistas com suas integrantes e da observação participante em evento.' $\mathrm{E}$ se insere em uma discussão mais ampla acerca dos processos de biomedicalização e novos modos de produção de subjetividades, profundamente marcados pelas diferenças de gênero. Nesse sentido, discutiremos como as novas práticas de percepção da fertilidade entre o grupo estudado são reveladoras de novos esforços na direção do monitoramento e aprimoramento da saúde que reencenam diferenças de gênero e também reatualizam noções de natureza e corporalidade.

O foco analítico relativo ao gênero é absolutamente central para entendermos o movimento descrito e para sugerir algumas interpretações mais gerais ao final do artigo. No tocante ao aparato de gênero, seguimos a proposta de Judith Butler (2003; 201 1), que argumenta que sua constituição se dá por meio de práticas reguladoras de formação e divisão dos sujeitos. A autora aponta para a heterossexualidade compulsória como um dos meios pelo qual se produz o gênero. Para ela,

a heterossexualização do desejo requer e institui a produção de oposições discriminadas e assimétricas entre "feminino" e "masculino", em que estes são compreendidos como atributos expressivos de "macho" e de "fêmea". [...] Ora, do ponto de vista desse campo, certos tipos de "identidade de gênero" parecem ser meras falhas do desenvolvimento ou impossibilidades lógicas, precisamente por não se conformarem às normas da inteligibilidade cultural (BUTLER, 2003, p. 39).

Essa hegemonia heterossexual exige e produz cada um dos termos do sistema como unívoco, e constitui, ao mesmo tempo, as duas únicas possibilidades de gênero no interior desse sistema binário oposicional que tende à hierarquização entre homens e mulheres (sempre coproduzidos junto a outros marcadores). Nesse sentido, é a partir de uma "naturalização" ou "biologização" da diferença sexual orientada primária e/ou necessariamente à reprodução que se assegura a estabilidade interna e a própria estrutura binária enquanto efeitos desse aparato.

Por outro lado, é também esse aparato que torna, para Butler, os gêneros inteligíveis, entendidos como aqueles que têm relações de coerência e continuidade entre sexo, gênero, prática sexual e desejo. Por meio de um conjunto de atos reiterados e citacionais no interior dessa estrutura reguladora, o gênero - por isso mesmo, performativo - adquire uma aparência de substância.

Pretendemos argumentar que é nesse sentido que as práticas de percepção da fertilidade, enquanto práticas performativas, ao mesmo tempo em que reforçam tais aparatos de gênero, em alguma medida também os reformulam.

\section{As Práticas de Percepção da Fertilidade e os Caminhos da Pesquisa}

Nesta seção vamos apresentar as práticas de percepção da fertilidade e descrever a construção do material que é analisado ao longo do texto. De início, é preciso situar o contexto

1 Estudo desenvolvido no contexto de realização da dissertação de mestrado intitulada Aparatos de produção subjetivo-corporais nas práticas de percepção da fertilidade, de Bruna Klöppel (2017), orientada por Fabíola Rohden, no Programa de Pós-Graduação em Antropologia Social da Universidade Federal do Rio Grande do Sul, com bolsa de mestrado da Capes. 
inicial do estudo. Em função de interesses de pesquisa no uso de artefatos hormonais por mulheres jovens, constatamos que, a partir de 2014, um número crescente de reportagens sobre os efeitos adversos do uso de anticoncepcionais hormonais foram publicadas, fazendo com que o debate na rede social Facebook ${ }^{2}$ também crescesse significativamente. Dentre os perigos associados a esses hormônios, figuravam as tromboses, embolias, acidentes vasculares cerebrais, depressão, cansaço, diminuição da libido e aumento da gordura corporal. Nesse quadro, muitas mulheres vêm suspendendo o consumo de hormônios contraceptivos, e práticas alternativas de contracepção - não necessariamente novidades - vêm sendo apresentadas e debatidas em grupos no Facebook e outras redes sociais.

É nesse contexto que surgiu, por exemplo, o grupo intitulado "Adeus Hormônios: contracepção não-hormonal", que se tornou o maior grupo relativo à contracepção em língua portuguesa existente nessa rede social com 130 mil perfis a ele associados, em 2017. Foi objeto de estudo da dissertação de Ananda Santos (2018), que constatou que há, nos discursos das participantes, preocupações com os efeitos colaterais da pílula anticoncepcional e demais contraceptivos hormonais, com a escolha do método contraceptivo não hormonal mais adequado, considerando as especificidades de cada sujeito, com debates em torno da ideia de "corpo natural e de produção de estilos de vida" (SANTOS, 2018). Em posição de destaque no grupo está a apresentação das possibilidades de contracepção não hormonal: preservativos, o diafragma, o dispositivo intrauterino de cobre, o coito interrompido e, finalmente, os métodos baseados na percepção da fertilidade.

Interessadas em saber mais sobre percepção da fertilidade, seguimos uma indicação feita no "Adeus, Hormônios" e demos início à participação em outro grupo no Facebook dedicado à discussão desse tipo de contracepção em particular. Vimos tal grupo crescer rapidamente no ano de 2015 e 2016, chegando a 13900 perfis membros a ele associados em novembro de $2016 .^{3}$ A participação nesse grupo foi o ponto do qual partimos para contatar as mulheres, sítios, livros e eventos que serão centrais na análise aqui empreendida.

As práticas de percepção da fertilidade envolvem, além da observação e registro da duração do ciclo menstrual, a observação, o registro e a interpretação dos chamados sinais primários de fertilidade, manifestos no/pelo corpo ao longo do ciclo. O fluido cervical, a temperatura basal e o colo do útero ${ }^{4}$ são os três sinais considerados primários pelas interlocutoras com quem conversamos. Tais práticas visam ao acompanhamento do ciclo menstrual e podem ter como objetivo a contracepção, a concepção e/ou o monitoramento da saúde. Os sinais primários indicam a fase do ciclo menstrual em que as praticantes se encontram e são interpretados cotidianamente de acordo com suas características e variações. Assim, buscam perceber se é possível engravidar ou se há problemas relacionados à saúde e à qualidade de vida que podem ser administrados.

O grupo no Facebook dedicado à discussão sobre essas práticas é descrito por suas moderadoras 5 como "um espaço para troca de informações e experiências sobre o ciclo menstrual, percepção da fertilidade e métodos naturais (não hormonais) de contracepção ou concepção e/ou monitoramento da saúde" (Grupo do Facebook, 2016, grifos no original). Da mesma forma, elas também incentivam que as praticantes não busquem respostas sobre seus ciclos menstruais no grupo enquanto não tiverem dados sobre o fluido cervical e/ou a temperatura basal para compartilhar. As respostas que buscam geralmente se referem ao período fértil, à relação entre seus hormônios e saúde, à ocorrência ou não de ovulação, à possibilidade de engravidar, dentre outras. Por fim, as moderadoras explicitam que um pré-requisito importante para a efetividade dos métodos, tanto para fins contraceptivos quanto para monitoramento da saúde, é que as praticantes tenham ciclos naturais - entendidos como aqueles que acontecem quando nenhum tipo de contracepção hormonal é utilizada -, sejam eles regulares ou não.

\footnotetext{
2 O Facebook, lançado em fevereiro de 2004, é a maior rede social do mundo e tem hoje mais de dois bilhões de perfis a ele associados. O sítio possibilita, via inscrição, a criação de perfis pessoais, bem como a criação, participação e compartilhamento de grupos, eventos, páginas, links para outros sítios, jogos, dentre outros. Além disso, o Facebook é uma empresa que lucra com os anúncios direcionados a públicos específicos em suas páginas e com a comercialização dos dados que coleta, embora não haja identificação individual de usuários. Nesse sentido, a plataforma não é neutra. Além disso, é importante ressaltar que, apesar de evidenciarmos ao longo do artigo parte da diferença que essa rede social faz na articulação pesquisada, essa descrição não é exaustiva por conta dos limites e enfoque de nossa pesquisa.

${ }_{3}^{3}$ Acesso em 08/1 1/2016. Esses números se referem à quantidade de perfis (contas registradas nessa rede social) que têm acesso às postagens do grupo; a forma de participação de cada um desses perfis é diversa. Não citamos o nome do grupo neste artigo propositalmente, a fim de dificultar sua localização e a exposição das pessoas citadas, cujos nomes utilizados aqui são fictícios.

${ }^{4}$ No caso de contracepção, as práticas são associadas a diferentes métodos contraceptivos; alguns se baseiam principal ou unicamente no acompanhamento do fluido cervical, enquanto o método da temperatura basal se baseia apenas na temperatura. Já os métodos sintotermais, utilizados pela maioria das entrevistadas, são aqueles que consideram ambos os sinais, sendo o acompanhamento da posição, textura e abertura do colo do útero opcional.

${ }^{5}$ As moderadoras do grupo são aquelas que podem escrever e editar a descrição do grupo, alterar suas configurações de privacidade, remover publicações, colocá-las em evidência e também bloquear e permitir a entrada de novos perfis membros
} 
Em termos da perspectiva metodológica adotada, tomamos esse grupo no Facebook como ponto de partida, mas sempre tensionando as possibilidades e limites associadas à própria ideia de constituição de um grupo. Como escreve Bruno Latour (2005), "(...) grupos não são silenciosos, mas efeitos provisórios de uma desordem constante produzida por milhões de vozes contraditórias sobre o que é um grupo e quem pertence ao quê" (LATOUR, 2005, p. 31, tradução nossa). ${ }^{6}$ Inspiradas por esse autor, buscamos as porta-vozes do grupo, aquelas que são ativas em "falar pela" existência dele. Fazem diferença fundamental na delimitação de suas fronteiras, já que são atuantes na criação das suas regras, seus objetivos, prioridades e formatos. Para Latour, não há grupo sem a existência daqueles que administram o recrutamento de aliados (LATOUR, 2005, p. 32) e entendemos que são as moderadoras e colaboradoras do grupo que fazem essa tarefa aqui.

Nesse sentido, o grupo do Facebook foi um ator - entre outros - que articulamos, não figurando como o campo empírico central. A partir dele, aproximamo-nos das participantes do "grupo da moderação"7 e, por entendermos como mais condizente com o nosso objetivo, consideramos pertinente a realização de entrevistas. A partir delas, poderíamos ter acesso a descrições mais acuradas das práticas cotidianas de percepção da fertilidade e, assim, compreender a quais elementos elas se relacionavam na vida de nossas interlocutoras. De forma complementar ainda, acessamos livros e sítios/blogs que nos foram indicados nas entrevistas e no grupo e, por fim, também participamos de um curso presencial ministrado por uma das entrevistadas, no qual ensinava os princípios das práticas de percepção da fertilidade. Todo esse material serviu de subsídio para a análise de cunho etnográfico que se segue.

Por meio do mapeamento deste cenário e do reconhecimento da formação deste grupo, foi possível caracterizar o que estamos chamando aqui de uma configuração particular, ligada à percepção da fertilidade. Utilizamos a noção de configuração, e também de articulação, enquanto uma rede de relações discursivo-materiais relativamente estáveis, que incluem presenças e ausências, além de suas condições de possibilidade. Esta perspectiva tem inspiração no conceito de hinterland, que John Law (2004) descreve como "um feixe de relações literárias e materiais mais ou menos rotineiras, dispendiosas e de extensão indefinida, que inclui afirmações sobre a realidade e as realidades mesmas; um hinterland inclui dispositivos de inscrição, e performa uma topografia de possibilidades de realidade, impossibilidades e probabilidades. Uma metáfora concreta para ausência e presença" (LAW, 2004, p. 160, tradução nossa). ${ }^{8}$ No caso da configuração aqui produzida, por um lado, trata-se de um projeto de autoconhecimento em relação ao corpo e de empoderamento ("feminino" ou "de pessoas com ciclos menstruais") diante da biomedicina, à qual as praticantes dirigem muitas críticas. Por outro lado, a percepção da fertilidade está ligada a uma busca não só pelo automonitoramento, mas também pelo aprimoramento da saúde, que tem seu sentido deslizado em outros termos, como "bem-estar" e "qualidade da vida", em uma lógica muito próxima à da biomedicina e seus recursos.

Quanto às entrevistas, conversamos com seis participantes do grupo da moderação. É relevante pontuar que todas as interlocutoras se conheceram a partir do encontro de seus perfis em grupos do Facebook que discutem contracepção não hormonal, com poucas delas vindo a se conhecer pessoalmente. Todas são bastante escolarizadas, estando pelo menos na graduação, com muitas delas em pós-graduação. Dentre as entrevistadas, todas se autoidentificam enquanto mulheres, brancas, estiveram ou estão em relacionamentos com homens cisgêneros, sem filhos e têm entre vinte e trinta anos. Três delas são moradoras do estado de São Paulo, uma de Santa Catarina, uma do Rio Grande do Sul e uma de Pernambuco.

Elas estão também engajadas em um curso de especialização a distância, intitulado "Programa de Treinamento de Profissionais em Saúde Reprodutiva Holística Justisse", ofertado pelo Justisse College, com sede em Edmonton, Canadá, sob a coordenação de Geraldine Matus. Esse é um dos três programas, certificados pela Association of Fertility Awareness Professionals (AFAP), que tem como objetivo a formação de instrutoras de métodos de percepção da fertilidade em um contexto secular e voltado ao empoderamento feminino em saúde.

\footnotetext{
${ }^{6}$ No original: "Groups are not silent things, but rather the provisional product of a constant uproar made by the millions of contradictory voices about what is a group and who pertains to what" (LATOUR, 2005, p. 31).

7 O "grupo da moderação" é formado pelas moderadoras e colaboradoras do grupo do Facebook. As colaboradoras auxiliam na moderação participando ativamente com publicações de tópicos sobre percepção da fertilidade, respondendo dúvidas que aparecem no grupo e envolvendo-se nas decisões sobre a moderação em um grupo na plataforma Telegram. Segundo seu sítio oficial, o Telegram é um software aplicativo de troca de mensagens instantâneas, fotos, vídeos, ligações e arquivos. Foi fundado em 2013 pelos irmãos russos Nikolai Durov e Pavel Durov. É promovido como mais seguro que seu concorrente WhatsApp, é gratuito e, segundo seus fundadores, não visa ao lucro. Disponível em https://telegram.org/faq. Acesso em 31/01/2020.

${ }^{8}$ No original: "a bundle of indefinitely extending and more or less routinised and costly literary and material relations that include statements about reality and the realities themselves; a hinterland includes inscription devices, and enacts a topography of reality possibilities, impossibilities, and probabilities. A concrete metaphor for absence and presence" (LAW, 2004, p. 160).
} 


\section{Natureza, Saúde e Empoderamento}

Essa nova articulação em torno da percepção da fertilidade tem como um de seus pontos centrais a controvérsia em torno da contracepção hormonal. Ao analisar a dinâmica do grupo no Facebook e as entrevistas realizadas, percebemos que as primeiras aproximações das práticas de percepção da fertilidade por parte de nossas interlocutoras se deram a partir da recusa aos hormônios contraceptivos e à consequente busca por uma forma alternativa de contracepção, não hormonal. Nesse sentido, é comum, nessa configuração, que as práticas de percepção da fertilidade, muitas vezes também promovidas como "contracepção natural", sejam colocadas em contraposição à contracepção hormonal, sendo apresentadas como alternativa "saudável" e "empoderadora" ao consumo desses hormônios. Se, por um lado, a literatura recente tem identificado cada vez mais o consumo de hormônios por mulheres para além da contracepção, com fins de aprimoramento, destacando os dilemas aí implicados (Fabíola ROHDEN, 201 7; 2018a; 2018b; Daniela MANICA; Marina NUCCI 2017; Livi FARO, 2016), por outro, temos aqui um cenário, a princípio, contrastante.

A percepção da fertilidade é enquadrada enquanto prática natural por não depender da ingestão de hormônios exógenos ao corpo. Segundo as interlocutoras, os hormônios contraceptivos impossibilitam a existência do ciclo menstrual, um ator considerado "natural" e "imprescindível à saúde". Nessa articulação, tal ciclo é descrito como composto por dinâmicas periódicas entre quantidades variáveis de hormônios, dentre os quais os protagonistas são o estrógeno e a progesterona, que levam à ocorrência de ovulação e da menstruação. Os hormônios contraceptivos, por sua vez, impediriam essa variação considerada "natural" por meio do consumo recorrente de hormônios similares aos produzidos pelos corpos. Sem tal variação, não há ovulação, nem fertilidade, nem menstruação. Natasha, estudante de Jornalismo, explica às ouvintes no curso presencial que acompanhamos sobre percepção da fertilidade:

Se a menstruação é uma consequência da ovulação, e quando você toma anticoncepcional você não ovula, não é menstruação, né? Na pausa do anticoncepcional, você sangra. Aquilo não é menstruação. Não é. Menstruação mesmo é um sangramento decorrente de uma ovulação, isso é uma menstruação. Outros sangramentos, que acontecem antes da ovulação ou não são decorrentes da ovulação, não são menstruação. Esse sangramento da pílula, por exemplo, ele é um sangramento de privação hormonal. Porque você estava recebendo hormônios e aí você parou de receber hormônios. Se você não tem ciclo, não é menstruação. Na pilula, o seu ciclo é reprimido (Natasha, 30/04/2016). ${ }^{9}$

Assim, nessa articulação, o ciclo menstrual faz parte da constituição de um "corpo natural" que menstrua, ovula, tem períodos férteis e variação hormonal. Por outro lado, os hormônios contraceptivos são considerados "artificiais" e, ao interferirem nesses ciclos, suprimindo essas variações hormonais particulares, trazem consigo os efeitos adversos. Assim, são produzidas fronteiras relativas ao "próprio corpo" ou ao "corpo natural", que inclui o ciclo menstrual e exclui hormônios contraceptivos, ainda que os últimos tenham sido consumidos diariamente por anos, como é o caso das praticantes com quem conversamos e também daquelas pesquisadas por Santos (2018). Esse corpo natural, para ser conhecido, deve estar livre das interferências dos contraceptivos hormonais.

Sendo assim, uma das motivações mais comuns para a interrupção do consumo de hormônios contraceptivos relatados no grupo sobre percepção da fertilidade é o desejo de "conhecer o próprio corpo", "conhecer o corpo natural" ou "conhecer a si própria". Esse autoconhecimento que se torna possível com a recusa aos hormônios contraceptivos e com a prática da percepção da fertilidade, por fim, é associado ao empoderamento em saúde. Segundo as interlocutoras, as práticas viabilizam um maior conhecimento e controle sobre o próprio corpo, o que, por sua vez, leva a decisões mais autônomas e conscientes em relação à saúde. Assim, a presença de ciclos menstruais é associada a uma vida mais natural, saudável e empoderada, conforme mostram os relatos de Ana, Luiza e Natasha:

É uma forma de empoderamento, não é? Você não ser dependente de um remédio que vai ferrar sua vida ou de alguma coisa invasiva. É ter esse poder maior sobre a saúde, e depender menos de médicos. [...] Eu acho que ninguém melhor do que a gente, com tudo isso

\footnotetext{
9 Aqui é apropriado lembrar o trabalho de Nelly Oudshoorn (1994), em que relata que, na época da criação dos hormônios contraceptivos, optou-se por uma forma de consumo no qual as pílulas deveriam ser tomadas cotidianamente por 20 dias que, seguidos de uma pausa, resultariam em um sangramento. No quinto dia de sangramento, o consumo da pílula deveria ser retomado. Oudshoorn (1994) chama a atenção para o fato de que essa "imitação" da menstruação foi considerada necessária para a adesão, por parte das mulheres, ao consumo da pílula e para a aceitação da opinião pública. A não ocorrência de sangramentos, sem uma associação à gravidez ou à menopausa, era entendida como um excesso de intervenção na natureza, o que causava fortes objeções morais (p. 119-120). Além disso, esse regime de medicação específico contribuiu para uma maior padronização da duração dos "ciclos menstruais", levando ao entendimento de que o "normal" e "regular" é que os ciclos menstruais durem sempre quatro semanas e os que diferem disso são considerados irregulares (OUDSHOORN, 1994, p. 136).
} 
de informação que a gente observa diariamente. É muito mais informação do que um médico consegue numa anamnese básica (Ana, 27/10/2016, grifos nossos).

Eu consigo tomar uma série de medidas pra melhorar minha saúde e facilitar a minha ovulação, fazer com que minha ovulação e meu ciclo sejam mais regulares, sim. Tem aquela frase: a gente tem medo do que não conhece. Você conhecendo é um passo para você parar de ter medo, para aceitar. Um passo para celebrar, quem sabe. Ao invés dessa carga muito negativa de que isso é sujo, é desprezível, isso é problemático. Acho que é empoderador nesse sentido (Luiza, 10/05/2016, grifos nossos).

É conhecer o próprio corpo, né? Como assim a gente não conhece o nosso próprio corpo?! Eu acho isso uma violência mesmo. É muita violência que as pessoas mintam pra gente deliberadamente: "Você pode engravidar a qualquer momento do ciclo", "Você pode ter um orgasmo e engravidar". É bem grave isso. Eu acho que tem total relação com empoderamento. E pra mulher ter realmente o poder de escolha, de qual método contraceptivo ela quer usar, seja ele hormonal ou não, ela precisa saber primeiro como o corpo dela funciona (Natasha, 06/05/2016, grifos nossos).

Como se pode depreender ainda, a percepção da fertilidade é entendida como prática de conhecimento que pode redistribuir a autoridade na relação com os médicos e reconfigurar as relações de gênero, gerando mais autonomia para as mulheres, principalmente no tocante à saúde e à administração da fertilidade.

Tais práticas são também reivindicadas enquanto contraconduta em relação à biomedicina, ligada a uma prescrição excessiva de hormônios contraceptivos das quais as interlocutoras são críticas. Além disso, desaprovam o autoritarismo médico e os interesses da indústria farmacêutica em lucrar via os corpos das mulheres. As falas de Rafaela, Ana e Luiza são ilustrativas do enquadramento dado à biomedicina nessa configuração. Transcrevemos abaixo:

A gente tem toda uma medicina hormonal que controla as mulheres de uma forma bem subjetiva. Na medicina ocidental, os médicos que detêm o conhecimento e são eles quem vão te dizer o que tu deves fazer. Eles não querem que tu saibas o que fazer com isso. Eles não querem que tu tenhas a tua autonomia. Eu acho que isso é um problema bem estrutural mesmo, desde lá da faculdade de Medicina (Rafaela, 15/07/2016, grifos nossos).

A pílula é o método perfeito para os ginecologistas, porque efeito colateral grave que pode dar, no sentido de a pessoa morrer ou ficar hospitalizada, é pouca gente. Aí esses efeitos secundários, como depressão e diminuição da libido, os médicos simplesmente acham que não existem, que é frescura. Ou então dizem pra usar um lubrificante ou que estamos com depressão porque nossa vida é uma merda, sei lá. Ou mandam ir a um psicólogo. Acho que a mulher não é levada a sério em muitas coisas (Ana, 03/09/2016, grifos nossos).

Existe também para todos os médicos de todas as especialidades uma pressão da indústria farmacêutica. Chega o representante e dá amostras grátis, a indústria patrocina congressos (Luiza, 10/05/2016, grifos nossos).

Os contraceptivos hormonais são articulados, portanto, a problemas relativos à desigualdade na relação entre médicos e pacientes e na relação entre médicos e indústria farmacêutica. Assim, entende-se que os efeitos nocivos à saúde decorrentes do uso dos contraceptivos são invisibilizados por essas relações de poder e denunciados.

Embora seja a crítica à contracepção hormonal que mobilize as mulheres a conhecer a percepção da fertilidade, constatamos que, conforme as práticas vão sendo apreendidas, o objetivo de monitoramento da saúde acaba se sobrepondo à contracepção. A partir das entrevistas, percebemos que a busca por "saúde, bem-estar e qualidade de vida" ocupava uma posição central na análise de seus ciclos menstruais. Enquanto nem todas as nossas entrevistadas utilizavam as práticas como contracepção, todas as utilizavam como uma forma de "monitorar a saúde".

A relação entre o monitoramento do ciclo menstrual, propiciado pelas práticas de percepção da fertilidade, e a saúde é, portanto, o que está no centro das preocupações de Talita, a partir das quais iniciamos esse artigo. Ela é uma de nossas interlocutoras que participa ativamente dessa configuração. Após deixar de consumir hormônios contraceptivos e dar início à prática de percepção da fertilidade como uma forma de se "reconectar com o corpo", percebeu que seu ciclo menstrual não correspondia ao considerado saudável nessa articulação.

\section{Entre Reconhecer, Monitorar e Aprimorar o Ciclo Menstrual}

Na sequência, pretendemos mostrar como as práticas de percepção da fertilidade vão se constituindo enquanto práticas de automonitoramento e autoaprimoramento relacionadas à saúde, identificadas na prática cotidiana como algo mais relevante e motivador, para as 
interlocutoras, do que a própria contracepção. No grupo do Facebook sobre percepção da fertilidade, a primeira orientação àquelas que buscam aprender as práticas é o "entendimento do ciclo menstrual". Para tanto, recomenda-se a leitura das publicações sobre ciclo menstrual do blog intitulado "O Lado Oculto da Lua" (Carolina ZANELLI, 2015a; 2015b). O blog - escrito por uma bióloga que pratica métodos baseados na percepção da fertilidade desde antes da criação do grupo no Facebook, do qual também participa - é apontado por nossas interlocutoras como um dos principais aglutinadores de conteúdo sobre percepção da fertilidade disponível em português. A descrição de um ciclo saudável presente nesse blog foi um dos elementos necessários para que Talita chegasse à conclusão de que não estava ovulando e, por conseguinte, de que seu ciclo menstrual não estava saudável.

Analiticamente, entendemos que não há "ciclo menstrual" como "substância" que escape às relações pelas quais é produzido e às performances nas quais é apresentado, sendo as práticas descritivas de um ciclo menstrual também prescritivas e, portanto, fundamentais na constituição de tal ciclo. Nesse sentido, são indispensáveis para as práticas de percepção da fertilidade enquanto forma de automonitoramento e aprimoramento, porque apresentam os sinais que devem ser monitorados e quais as indicações que dão em termos de saúde e qualidade de vida. Por essa razão, resumimos como o ciclo menstrual é apresentado nesse blog seguido da descrição da busca de Talita pela produção de um ciclo similar, considerado saudável.

Segundo uma das postagens do blog, o início da menstruação marca o começo de um ciclo menstrual e tem como ponto de referência fundamental um evento do ciclo anterior, a ovulação, sendo entendida como fruto dela. A chamada fase folicular tem seu início no primeiro dia de menstruação e compreende o processo que vai do início do ciclo até a liberação do óvulo pelo ovário, chamada ovulação. O muco cervical, produzido pelo colo do útero sob o estímulo do estrogênio, é descrito como "um fluido 'natural e saudável"' que, durante a fase folicular, vai se modificando: é mais seco no início e se torna mais úmido conforme a aproximação da ovulação (ZANELLI, 2015b).

Ao longo da fase folicular, ainda, descreve-se que há um progressivo aumento do humor e da energia, que "podem estar um pouco mais em baixa" durante a menstruação e que "estão ótimos" logo antes da ovulação. Além disso, o fim do período folicular (quando da proximidade da ovulação) pode estar associado, segundo a publicação, ao "inchaço das mamas e dos lábios da vulva". Todas essas características - relativas à umidade e à presença do fluido cervical, ao humor e à energia e aos inchaços citados - são associadas de forma primordial ao aumento do estrógeno e à consequente proximidade da ovulação.

A segunda fase do ciclo menstrual, chamada fase lútea, inicia com a ovulação e termina com a menstruação seguinte. É caracterizada pela produção de progesterona (que não acontece antes da ovulação), que impede a ocorrência de uma segunda ovulação no ciclo menstrual. Ao fim da fase lútea, com a queda dos níveis de estrógeno e progesterona, a menstruação ocorre. O principal sinal de fertilidade associado à fase lútea é o aumento da temperatura corporal basal. Segundo consta no blog,

Apesar do significado do nome, a progesterona (assim como os outros hormônios!) é importante não só para a gravidez, mas também pro ciclo menstrual e pra saúde em geral, e tem diversos efeitos sobre todo o corpo! Um desses efeitos é aumentar o metabolismo, e isso se reflete no aumento da temperatura basal. A temperatura basal é a temperatura do corpo em estado de repouso, medida com um termômetro específico logo após acordar, antes mesmo de se levantar. Sob o efeito da progesterona, a temperatura basal aumenta após a ovulação (ZANELLI, 2015b).

Além disso, com a queda dos níveis de estrógeno e progesterona ao fim da fase lútea, a temperatura basal também cai. Em relação ao fluido cervical, há, durante a fase lútea, uma progressiva redução da umidade ou uma interrupção na sua produção. Quanto à energia e ao humor, são descritos como mantidos altos no início da fase lútea, contudo "vão caindo aos poucos". A duração considerada saudável de um ciclo menstrual completo é, conforme a publicação, de 24 a 35 dias.

A partir dessa descrição de um ciclo menstrual e hormonal, Talita apreende o que é um ciclo menstrual saudável e passa a se relacionar com os sinais - muco, temperatura, humor e outros sintomas - que poderiam materializá-lo em seu cotidiano. Torna-se capaz, por meio do ativo automonitoramento, de identificar os "problemas" do seu próprio ciclo quando medidos a partir dessa descrição. Não basta, contudo, identificá-los. É necessário também aprender a produzir um ciclo menstrual que possa reconhecer como saudável. É disso que se trata o aprimoramento na percepção da fertilidade.

Desde 2015, Talita vinha medindo e registrando sua temperatura basal cotidianamente com a ajuda de um termômetro. Contudo, não conseguia identificar um aumento de temperatura seguido de um sangramento, em até 16 dias, que pudesse ser considerado menstrual. Tampouco confirmava gravidez, que poderia ser outro motivo de não ter variação visível em suas temperaturas 
nem sangramento menstrual. Assim, assumia que seu corpo não estava produzindo progesterona e, portanto, não estava ovulando. Da mesma forma, também analisava e registrava seu muco vaginal cotidianamente quando ia ao banheiro e, ainda assim, não conseguia distingui-los. Talita "só conseguia chegar à conclusão de que estava seca". Isso também era lido como quantidade insuficiente de estrógeno, hormônio responsável por dar umidade ao muco e que, em seu pico, possibilitaria a ocorrência da ovulação e de uma melhora em seu humor.

Nesse sentido, a busca de Talita pela ovulação era também a busca por conseguir quantidades suficientes de estrógeno que possibilitariam a ovulação e a produção de progesterona que decorre dela. Não ovular, dessa forma, indicava que não tinha a quantidade ideal desses hormônios; quando conseguisse alcançá-los, estaria então melhor em termos de saúde, bem-estar e qualidade de vida. Por isso, Talita investiu em tomar vitex, erva que comprou em uma farmácia on-line de São Paulo, que não exigia prescrição médica. Pela mesma razão, tomou também maca peruana e suplementação de magnésio e de zinco, que considerava "naturais" e que poderiam "ajudar o corpo a se regular". Além do endocrinologista, Talita também frequentava uma ginecologista. Em uma das consultas, a médica lhe disse que nunca havia ouvido falar do vitex e da maca peruana. Talita diz ter pensado, embora não dito a ela: Anote aí porque eu quero ver você se atualizando. Perguntamos então para que exatamente ela tomava o vitex, ao que ela respondeu:

Pra casos de muito tempo sem ovulação. Estimular a hipófise, estimular produção de estradiol, o principal estrógeno do processo ovulatório, para que atinja nível satisfatório para a produção de um folículo que consiga romper. [...] Maca peruana eu também tentei. Falei pra ela [ginecologista], e levei frascos pra ela e mostrei. Do vitex e da maca peruana. Estava tomando há duas semanas, pouco tempo. Além disso, suplementação de magnésio e zinco, que seriam os nutrientes mais inofensivos de se fazer suplementação. Perguntei o que ela achava, ela disse que ia pesquisar sobre a maca peruana e o vitex. E sobre os suplementos, achou ótimo. Ela indica em casos inflamatórios também. Com certeza mal não ia fazer. Ela fez prescrição como eu queria. Pedi 90 cápsulas, 3 meses para poder dar o retorno (Talita, 08/08/2016).

Já na segunda conversa com Talita, ela disse que o consumo de magnésio e zinco ${ }^{10}$ estava começando a ter efeitos. Contou também ter parado de tomar o vitex por não ter sentido diferença, mas ter voltado a tomar a maca peruana. Seria uma forma também de estimulação da produção de estrógeno, mas dizia tomar em "caráter experimental, não muito regrado". Além disso, relatou ter começado a investir em uma melhora na alimentação, embora não se tratasse de "virar um monge alimentício", mas de "observar como o corpo reage a certas coisas, respeitando a individualidade". Além dessas, citou outras práticas que considerava que poderiam influenciar na produção de hormônios, como dormir melhor, fazer psicoterapia, exercícios físicos, dentre outras atividades que considerava cuidados consigo mesma.

Na articulação em torno da percepção da fertilidade, busca-se não só a produção dos hormônios, mas o equilíbrio ideal entre eles, já que a interação no mundo tenderia a desequilibrálos. Os hormônios contraceptivos figuram como uma das causas principais do desbalanceamento, mas também a alimentação de má qualidade, a grande carga horária de trabalho, o estresse, o sedentarismo, a distribuição do tempo de trabalho baseado em um padrão de produtividade do corpo masculino (que seria linear, e não cíclico), o machismo em diversas formas, dentre outros. Como, portanto, rebalancear os hormônios? Alguns sítios e livros aos quais as interlocutoras fazem referência de forma recorrente utilizam termos como: "restaurar saúde menstrual e fertilidade", "reparar o ciclo", "saúde hormonal holística", "saúde hormonal", dentre outros. Além disso, a edição de $20^{\circ}$ aniversário do Taking Charge of Your Fertility (2015), considerado pelas interlocutoras a "bíblia da percepção da fertilidade", teve um capítulo novo incluído, intitulado "Natural Ways to Balance Your Hormones".

As mudanças sugeridas por esses sítios e livros, na busca por balancear os hormônios, dizem respeito a essas mudanças nas quais Talita se empenha: alimentação, prática de exercícios, redução do contato com os chamados disruptores endócrinos e do estresse, qualidade do sono e consumo de suplementos vitamínicos e fitoterápicos, também chamados "remédios naturais". Nas conversas com outras interlocutoras, essas mudanças também apareceram. Rafaela, bióloga residente no interior do Rio Grande do Sul, comentou conosco suas mudanças na alimentação e no consumo de suplementos vitamínicos com a finalidade de melhorar o equilíbrio entre estrógeno e progesterona em seus ciclos menstruais:

Geralmente procuro me alimentar de coisas que eu sei que vão ser boas pro meu corpo e para o metabolismo do estrogênio. Eu procuro sempre comer verduras de cor verde-escuro, rúcula, agrião, couves. [...] O que eu fiz foi aumentar as coisas boas, mas não cortei as coisas ruins.

\footnotetext{
${ }^{10}$ A promoção dessas duas suplementações é realizada em termos de suas propriedades anti-inflamatórias, já que a inflamação - atribuída ao consumo de comidas derivadas do trigo e do leite, cigarro e toxinas ambientais - teria a ver com problemas relacionados aos receptores hormonais. Sem o funcionamento desses receptores, o estrógeno não teria efeito e a ovulação não seria possível. Tais relações geralmente são associadas ao sítio www.larabriden.com, mantido pela naturopata Lara Briden e bastante citado pelas interlocutoras.
} 
Como açúcar todos os dias. [...] Vitamina $D$, eu tinha feito exame e estava com insuficiência. $E$ vitamina $D$ está totalmente relacionada com a fertilidade. O magnésio e a vitamina $E$, eu comecei a tomar para lidar com o problema das dores nos seios. Mas eu estou tomando há um mês e meio, então é ainda um pouco cedo pra ter algum resultado. Provavelmente eu vou começar um tratamento novo para isso com vitamina B6 e que é pra ajudar a produção da progesterona. Porque a dor nos seios é esse excesso de estrogênio em relação à progesterona. Tem algum desbalanço aí. [...] Eu mando manipular essas coisas. [...] Eu procuro pela internet farmácias de manipulação que manipulem o remédio sem ter receita médica, daí consigo por ali (Rafaela, 30 anos, 15/07/2016).

Percebe-se, como é também o caso de Talita, que as farmácias de manipulação que realizam vendas pela internet, sem a exigência de receita médica, fazem diferença no acesso à suplementação vitamínica, dispensando a consulta médica.

Beatriz, à época graduanda em um curso de ciências humanas, externou sua preocupação com os efeitos dos xenoestrógenos em seu ciclo menstrual e descreveu suas atitudes que visavam a atenuar o desbalanceamento causado por ele. Além disso, relatou suas mudanças em relação à alimentação e ao sono, bem como as dificuldades práticas em torno da manutenção desses hábitos em seu cotidiano quando da necessidade de se relacionar com pessoas próximas:

Parei de usar produtos de limpeza convencionais, porque também estava estudando o porquê de essas coisas serem ruins. Tipo o xenoestrógeno, que estão nos produtos químicos, que são essas coisas que alteram. São substâncias muito parecidas com estrógeno e que têm em milhares de coisas que a gente usa, principalmente coisas de plástico. E essa coisa faz com que o seu corpo entenda que você tem muito mais estrógeno, e isso causa várias desregulações hormonais. [...] Comecei a comer menos soja, por causa do estrógeno, e comer mais carne, tentar comer mais comida orgânica, dormir no escuro. [...] Quando coloquei cortinas no quarto, que comecei a dormir no escuro, melhorou a regularidade do meu ciclo. Mas eu viajo muito pra São Paulo porque meus pais e meu namorado moram lá. E aí quando eu estou lá, a minha vida muda muito. [...] Volta tudo pra trás, sabe? (Beatriz, 24 anos, 06/05/2016).

Ana, mestranda em Matemática em uma universidade pública no sul do país, relatou uma outra prática para lidar com o excesso de estrógeno em relação ao de progesterona (a chamada "dominância estrogênica"): o banho de assento.

Na minha primeira reunião com a instrutora do curso, ela perguntou o que eu achava do ciclo. E se eu queria mudar alguma coisa. Porque não estão completamente saudáveis, tem uns padrões de muco que eu sei que talvez seja uma dominância estrogênica. Só que eu meio que não espero estar totalmente saudável do jeito que eu estou agora: meio deprimida, sedentária, acima do peso. [...] Ela perguntou sobre o meu muco e eu falei que está meio pastoso, amarelado. E ela me indicou o vaginal steaming, que é uma prática antiga. Basicamente você faz um chá bem forte de algumas ervas, aí tem ervas indicadas para coisas diferentes também. Aí faz "cabaninha" ali pro vapor ficar contido. Senti que realmente limpa mesmo (Ana, 29 anos, 27/10/2016).

Além disso, contou-nos de suas investidas na tentativa de mudar a alimentação e das dificuldades em relação à prática de exercícios físicos, que atribui à depressão, a qual também tem se empenhado em superar via terapia. A saída que lhe parece mais acessível, nesse momento de sua vida, é a suplementação, sobre a qual realiza pesquisas na internet com o auxílio do grupo da moderação com o qual dialoga via Telegram. Segundo suas palavras:

Eu também andava muito cansada e comecei cortando o glúten, porque percebi que podia ser isso. [...] Sim, eu sou sedentária e pode ser isso uma das causas. Mas poxa, quando você está sem energia, é muito difícil você fazer exercício físico. Eu também estou deprimida, fazendo terapia, buscando mesmo crescimento pessoal. [...] Mas tá, exercício físico não rola, então o que pode ser? Posso estar com deficiência de alguma coisa. A Geraldine [Matus] não é tão fã de suplementar. Só que como eu estava muito assim, "preciso de alguma coisa", eu disse: "Al, vou experimentar e se não der efeito, eu paro. E na pior das hipóteses, é só um, né? É só magnésio, só mineral." [...] E eu tenho aquele histórico de depressão, e depressão está associada também à deficiência de vitamina $D$, e vitamina $D$ a gente consegue mais por causa do sol. E a gente passou esse período de inverno aqui, eu sempre de manga comprida, muito tempo em casa. Então eu fiz meio que por conta própria. Não se deve fazer assim, mas eu dei uma lida na internet. Baseado em tudo que eu li, achei que era seguro e fiz (Ana, 29 anos, 27/10/2016).

Percebe-se, por intermédio desses relatos, que há uma ênfase, sobretudo, na mudança da alimentação e no consumo de "remédios naturais", os suplementos vitamínicos e ervas. A prática de exercícios físicos aparece como relevante, mas parece figurar como a última opção, dada sua relativa dificuldade quando em comparação com outras opções mais facilmente inseridas na rotina. As práticas terapêuticas, como psicoterapia e yoga, também aparecem, mas não se dispensa muitas palavras sobre seus efeitos diretos nos ciclos menstruais ou na saúde. 


\title{
Biomedicalizaçāo, Produção de Subjetividades e Gênero
}

Nesta seção final gostaríamos de argumentar como as novas práticas de percepção da fertilidade descritas acima estão associadas a processos mais amplos, caracterizados pela literatura como: biomedicalização, aprimoramento e produção de subjetividades. E, ao final, pretendemos articular isso ao aparato de gênero, retomando este eixo central do artigo. A primeira aproximação se dá em relação àquilo que Adele Clarke e colegas (2010) vêm chamando de "biomedicalização", referindo-se às mudanças na constituição e práticas da biomedicina que ocorrem desde meados dos anos 1980, nas quais os Estados Unidos foram precursores. Tais mudanças estão relacionadas, sobretudo, às inovações científicas e não se restringem à biomedicina em um sentido estrito. Dizem respeito a cinco processos principais, descritos pelas autoras da seguinte forma:

\begin{abstract}
1) Uma nova economia biopolítica da medicina, saúde, doença, modos de vida e morte que forma uma arena cada vez mais densa e elaborada na qual conhecimentos biomédicos, tecnologias, serviços e capitais são cada vez mais coconstituídos; 2) Um foco novo e intensificado na saúde (em adição a doenças e lesões), na otimização e aprimoramento por vias tecnocientíficas e na elaboração do risco e vigilância no nível individual, de grupos de nicho e de população; 3) A tecnocientificização das práticas biomédicas nas quais intervenções para tratamento e aprimoramento são progressivamente mais apoiadas em ciências e tecnologias, são concebidas nesses mesmos termos, e são cada vez mais prontamente aplicadas; 4) Transformações da produção do conhecimento biomédico, gerenciamento de informação, distribuição e consumo; e 5) Transformações dos corpos e a produção de novas identidades tecnocientíficas em nível individual, coletivo e de população (ou grupos de nicho) (CLARKE et al., 2010, p. 1-2, tradução nossa). ${ }^{11}$
\end{abstract}

Seria a partir da conformação desse novo "regime de verdade" associado à biomedicalização que a saúde passa a ser entendida como uma conquista pela qual o indivíduo é responsável, o que deve ser buscado a partir do consumo das informações e recursos disponíveis, práticas de cuidado e vigilância de si, atitudes de prevenção a doenças e aprimoramento da saúde. $O$ foco deixa de estar na doença para se dirigir às mudanças nos comportamentos e no estilo de vida. Os deslizamentos entre as noções de saúde, bem-estar e qualidade de vida evidenciam isso. Não se trata mais, portanto, de focar em doenças ou em corpos doentes, mas de melhorar o que pode ser melhorado, por meio de uma transformação simultânea do corpo e do self. Para Clarke e colegas (2010), o aprimoramento tem a ver com intervenções que vão além de correções de problemas médicos, na direção de ideais de aperfeiçoamento individual, marcados pela crença de que é possível sempre melhorar e por uma centralidade das relações de consumo.

Nessa articulação em torno da percepção da fertilidade, percebemos uma relação ambígua, porém marcada pela biomedicalização. Trata-se de um foco intensificado na saúde que não passa pela cura de corpos patologizados, mas preza pelo aprimoramento. Isso é evidente quando constatamos que os "problemas" identificados nos ciclos menstruais não são tratados como doenças. São apenas pontos de partida na busca por recursos que visam ao melhoramento do ciclo menstrual e, por conseguinte, de diferentes dimensões das vidas das praticantes. Muitos desses recursos passam pela tecnociência, e vão desde softwares aplicativos para monitoramento do ciclo e termômetros de precisão a recursos farmacêuticos como suplementos vitamínicos ou à base de ervas. Além disso, recursos associados a práticas tradicionais também são valorizados, como banhos de assento com chás, ainda que a utilização da língua inglesa para nomear a prática - o "vaginal steaming" citado por Ana - possa fazer diferença em sua apresentação. A afirmação da centralidade da ciência, no entanto, é explícita na ênfase constante nos "dados" e "evidências".

O ciclo menstrual - em sua íntima vinculação tanto a variações hormonais específicas quanto à ovulação e aos sangramentos ligados a ela - é lido como "natural" e inserido em uma dinâmica onde sua ausência é sinal de falta de saúde. Contudo, sua presença ainda não se revela suficiente na prática, já que é possível ainda torná-lo mais saudável, aprimorá-lo. Isso é justificado em termos de uma suposta "natureza" anterior que foi transformada pelo estilo de vida atual, associado ao capitalismo, ao machismo e à biomedicina, e que viria a ter como uma de suas expressões o "consumo indiscriminado" da contracepção hormonal hoje. Tal perspectiva é

\footnotetext{
"No original: "1 a new biopolitical economy of medicine, health, illness, living, and dying which forms an increasingly dense and elaborate arena in which biomedical knowledges, technologies, services, and capital are ever more co-constituted; 2 a new and intensifying focus on health (in addition to illness, disease, injury), on optimization and enhancement by technoscientific means, and on the elaboration of risk and surveillance at individual, niche group, and population levels; 3 the technoscientization of biomedical practices where interventions for treatment and enhancement are progressively more reliant on sciences and technologies, are conceived in those very terms, and are ever more promptly applied; 4 transformations of biomedical knowledge production, information management, distribution, and consumption; and 5 transformations of bodies and the production of new individual, collective, and population (or niche group) level technoscientific identities" (CLARKE et al., 2010, p. 1-2).
} 
contrastante com aquela descrita por Manica (201 1) no registro dos investimentos biomédicos em torno da "supressão da menstruação" como forma de produzir uma outra qualidade de vida para as mulheres.

Nesse sentido, as interlocutoras consideram necessário que se invista em "consertar" as consequências dessa intervenção humana indevida, a partir de outra forma de intervenção, que retome a orientação "natural" e, portanto, mais saudável, do corpo. Assim, é em torno de uma suposta maior proximidade da natureza, em contraposição à artificialidade da biomedicina, que a utilização de recursos farmacêuticos à base de ervas e suplementos vitamínicos é legitimada, enquanto o uso de hormônios é criticado. O trabalho de Ivone de Sá (2012) sobre como se estabilizaram as alternativas fitoterápicas à terapêutica de reposição hormonal, e como a categoria da "natureza" é operada nessa configuração também nos ajuda a pensar sobre a utilização de "remédios naturais", seu sucesso entre os críticos da biomedicina e sua inserção na indústria farmacêutica. O vitex, erva utilizada por Talita quando em busca da ovulação, é um desses remédios que substituem a terapêutica hormonal e sobre o qual Sá (2012) se debruça. A associação da "natureza" a uma ausência de riscos parece estar presente em ambos os casos.

Outro indicativo da relação entre a percepção de fertilidade e a biomedicalização diz respeito às formas de comunicação e de troca de informação entre as participantes, mediadas por frutos do desenvolvimento tecnocientífico, dos quais são exemplos plataformas como Facebook e Telegram. Os materiais que acessam também são muitas vezes coletados a partir de downloads, bem como a busca por artigos científicos, blogs ou compra de suplementos é feita em plataformas dependentes da internet. De forma relevante, portanto, essa articulação é efeito também de uma mudança na distribuição, gerenciamento e consumo da informação que não está submetida a fronteiras geográficas bem delimitadas e possibilita, ou facilita, certos tipos de encontros.

Essas articulações geram então novas subjetividades ou, nas palavras de Clarke e colegas (2010), identidades tecnocientíficas. Ao mesmo tempo em que se investe nessas mudanças corporais e de estilo de vida, concepções de identidade são a elas positivamente associadas: trata-se de mulheres autônomas, empoderadas, feministas, saudáveis, cientificamente informadas e mais próximas à natureza, que se responsabilizam individual e coletivamente pela busca por aprimoramento. Além disso, a identificação e resolução desses problemas encontrados nos ciclos menstruais são individualizadas ou, nas palavras de Clarke e colegas (2010), "customizadas". Tal processo de "customização", associado ao aprimoramento, é definido pelas autoras como um processo no qual há um adicional em relação às práticas de medicalização, que eram orientadas por desejos de normalização por meio da homogeneização: as práticas de biomedicalização estratificada realizam desejos de diferenciação personalizada (CLARKE et al., 2003, p. 181). Assim, busca-se a realização de projetos individuais por meio dos recursos de personalização, que no caso específico aqui tratado, inclui a produção de gráficos individuais para monitoramento dos "problemas", bem como "soluções" individualizadas, medição de temperatura e análise cotidiana do muco cervical, além do compartilhamento de tais informações com outras praticantes e consumo constante de informações em prol do melhoramento da saúde.

Além disso, ainda segundo Clarke e colegas (2010), "a governamentalidade biomédica de 'conhecer a si mesmo', associada às técnicas corporais, geralmente está vinculada a um discurso neoliberal de consumidor que promove ser 'pró-ativo' e que 'toma o controle da própria saúde'" (CLARKE et al., 2003, p. 181, tradução nossa). ${ }^{12}$ Nessa configuração em torno da percepção da fertilidade, esse "tomar o controle da própria saúde" assume a forma de uma reivindicação feminista, já que se entende enquanto contraconduta em relação ao conhecimento e à intervenção biomédicos considerados patriarcais. Trata-se de um movimento herdeiro, em certo sentido, do movimento de autoajuda feminista, que teve início nos Estados Unidos no final dos anos 1960 e que acabou se espalhando por várias partes do mundo, incluindo o Brasil (Michelle MURPHY, 2004; 2012; Bruna KLÖPPEL, 2017).

Assim, essas novas "identidades tecnocientíficas", ou seja, essas novas subjetividades caracterizadas por relações específicas com as tecnociências, não são identidades totalmente novas. A ligação entre feminismo, saúde, automonitoramento e autonomia já estava presente no movimento de autoajuda feminista. Contudo, a governamentalidade biomédica modifica as formas de acesso e performances relacionadas a essas identidades, incluindo novos elementos. A consolidação mesma da necessidade de um monitoramento individual cotidiano do ciclo menstrual, por meio do uso de artefatos tecnocientíficos, remete a uma aproximação de tal governamentalidade. Além disso, o foco no aprimoramento, a centralidade dos hormônios, o consumo de recursos como remédios à base de ervas e suplementações, o uso de artefatos como os termômetros e aplicativos para celulares, além do protagonismo do Facebook e da internet, são próprios dessa configuração em torno da percepção da fertilidade.

12 No original: "The biomedical governmentality to 'know thyself' that is associated with such bodily techniques often relies on a neo-liberal consumer discourse that promotes being 'proactive' and 'taking charge' of one's health" (CLARKE et al., 2003, p. 181) 
Dessa forma, pode-se dizer que tais "identidades tecnocientíficas" estão ligadas, por um lado, a projetos feministas coletivos de "empoderamento" e de valorização de um corpo associado primariamente ao feminino e, por outro, à responsabilização individual pela saúde e pelo aprimoramento, presente na busca por se tornar "mais saudável", "mais fértil" e "mais natural", o que viria a propiciar também um aumento do "bem-estar" e da "qualidade de vida".

Para finalizar, cabe ainda retomar a argumentação inspiradora de Butler (2003) que citamos no início do artigo e que nos permite entender como a configuração estudada reencena as normas de gênero. Entendendo as práticas de percepção da fertilidade como processos de materialização, traçamos a seguir algumas das associações que são estabilizadas nesses processos e que se referem ao aparato de gênero, seja no sentido de reforçá-lo ou reconfigurá-lo.

Por um lado, os agenciamentos em torno da percepção da fertilidade continuam a colocar o sexo, ligado à natureza, como uma matéria-prima dada e, embora passível de ser modificada, pertencente a um domínio anterior e "original". Nesse domínio, o ciclo menstrual, o estrógeno e a progesterona são os protagonistas. Dessa forma, ao reproduzirem uma diferenciação entre sexo e gênero, acabam por "naturalizar" a diferença sexual e hormonal, em termos binários, orientada à reprodução. Nesse sentido, acabam assim por reforçar o aparato de gênero como entendido por Butler (2003). Além disso, a hierarquização, marcada pela noção de "saúde", "bem-estar" e "qualidade de vida", entre as práticas associadas a uma natureza e as práticas entendidas como mais artificiais acabam por abrir espaço para uma deslegitimação ou inferiorização de outros corpos e identidades, menos próximos dessa "natureza" lida como "mais saudável", principalmente em um quadro de responsabilização individual no qual a saúde é um atributo moral.

Por outro lado, no entanto, há o reconhecimento da possibilidade de descontinuidade entre sexo, gênero, prática sexual e desejo, o que reformula o aparato de gênero descrito por Butler. A orientação dessa natureza (ligada aos ciclos menstruais) tem uma associação mais reiterada à saúde do que à mulheridade ${ }^{13}$ ou à reprodução, sendo esses últimos performados em conexão ao domínio do gênero (em contraposição a sexo) e do social (em contraposição ao natural). É central, portanto, a reafirmação dessa dicotomia hegemônica e constitutiva do "Ocidente moderno". Por fim, é possível considerar a politização da saúde e do ciclo menstrual visando à reconfiguração das relações de gênero, de forma a torná-las mais igualitárias, como uma tentativa de modificação dos efeitos do aparato de gênero - a tendência à hierarquização entre homens (médicos) e mulheres (pacientes) - sem atacar a "naturalização" da diferença sexual e a estrutura binária no nível do sexo.

Ainda no tocante a essa "naturalização", é necessário destacar o que as práticas de percepção da fertilidade reformulam no plano hormonal, que constitui o foco mais recente da biologização ou "substancialização" da diferença sexual (ROHDEN, 2008; 2017). Representam mais um capítulo no que se refere aos antigos debates e controvérsias recentes relativos à utilização de hormônios para diferentes fins (Nelly OUDSHOORN, 1994; Celia ROBERTS, 2007; FARO, 2016). Se por um lado, estão ligados a uma natureza dada e anterior, bem como à saúde e ao bem-estar, também são remodelados de maneira significativa. Hormônios historicamente associados a "corpos femininos", como o estrógeno, são articulados aqui em torno de noções de libido, criatividade, produtividade e aumento da energia, geralmente ligados à testosterona e à masculinidade, na biomedicina. No entanto, os momentos do ciclo menstrual caracterizados pela ausência ou diminuição do estrógeno são performados enquanto em falta em relação a esses atributos, enquadrados como presentes constantemente nos "corpos masculinos", definidos como "sempre férteis". Os atributos associados à ausência do estrógeno são, em contrapartida, positivados como momentos necessários de reflexão e autocuidado, havendo um questionamento do valor atribuído a uma produtividade necessariamente em ascendência constante.

Já a forma como essa "natureza hormonal" determina os comportamentos não é questionada. Ademais, os esquemas binários são mantidos na associação mais íntima de alguns tipos de corpos ao estrógeno e à progesterona, e outros à testosterona, pelo menos no nível da "natureza", constitutivo e primordial. Nesse sentido ainda, para as partidárias da percepção da fertilidade, e suas referências "naturais", na medida em que o consumo de hormônios é ligado a uma artificialidade contrária à natureza e, portanto, menos saudável, aqueles corpos e identidades que os consomem, seja por que motivo for, estariam em contraposição a uma "vida saudável".

\section{Referências}

BUTLER, Judith. Problemas de gênero: feminismo e subversão da identidade. Rio de Janeiro: Civilização Brasileira, 2003.

BUTLER, Judith. Bodies that Matter: On the Discursive Limits of "Sex". New York: Routledge, 2011.

\footnotetext{
${ }^{13}$ Entendemos "mulheridade" como o estatuto ontológico atribuído situacionalmente ao "ser mulher", que entendemos estar sempre em disputa.
} 
CLARKE, Adele E.; SHIM, Janet; MAMO, Laura; FOSKET, Jennifer; FISHMAN, Jennifer (Eds.). Biomedicalization: Technoscience and Transformations of Health and IIIness in the U.S. Durham: Duke University Press, 2010.

FARO, Livi. "Mulher com bigode nem o diabo pode": um estudo sobre testosterona, sexualidade feminina e biomedicalização. 2016. Tese (Doutorado) - Programa de Pós-Graduação em Saúde Coletiva, Instituto de Medicina Social, Universidade do Estado do Rio de Janeiro, Rio de Janeiro, Rio de Janeiro, Brasil.

KLÖPPEL, Bruna. Aparatos de produção subjetivo-corporais nas práticas de percepção da fertilidade. 2017. Dissertação (Mestrado) - Programa de Pós-Graduação em Antropologia Social, Universidade Federal do Rio Grande do Sul, Porto Alegre, Rio Grande do Sul, Brasil.

LATOUR, Bruno. Reassembling the social: An introduction to actor-network theory. Oxford: Oxford University Press, 2005.

LAW, John. After Method: Mess in social science research. New York: Routledge, 2004.

MANICA, Daniela Tonelli. "A desnaturalização da menstruação: hormônios contraceptivos e tecnociência". Horizontes Antropológicos, Porto Alegre, v. 17, n. 35, p. 197-226, 2011 . Disponível em http://www.scielo.br/scielo.php?script=sci_arttext\&pid=S0104-7183201 1000100007. Acesso em 31/01/2020.

MANICA, Daniela; NUCCl, Marina. "Sob a pele: implantes subcutâneos, hormônios e gênero". Horizontes Antropológicos [online], v. 23, n. 47, p. 93-129, 2017. Disponível em http://www.scielo.br/ scielo.php?pid=S0104-7183201 7000100093\&script=sci_abstract\&tIng=pt. ISSN 1806-9983. https:// doi.org/10.1590/s0104-71832017000100004. Acesso em 31/01/2020.

MURPHY, Michelle. "Immodest Witnessing: The Epistemology of Vaginal Self-Examination in the U.S. Feminist Self-Help Movement". Feminist Studies, v. 20, n. 1, p. 115-147, 2004.

MURPHY, Michelle. Seizing the means of reproduction: entanglements of feminism, health, and technoscience. Durham/London: Duke University Press, 2012.

OUDSHOORN, Nelly. Beyond the natural body: an archeology of sex hormones. London: Routledge, 1994.

ROBERTS, Celia. Messengers of Sex: Hormones, biomedicine and feminism. New York: Cambridge University Press, 2007.

ROHDEN, Fabíola. "O império dos hormônios e a constituição da diferença entre os sexos". História, ciências, saúde - Manguinhos, Rio de Janeiro, v. 15, p. 133-152, 2008.

ROHDEN, Fabíola. "Vida saudável versus vida aprimorada: tecnologias biomédicas, processos de subjetivação e aprimoramento". Horizontes antropológicos [online], v. 23, n. 47, p. 29-60, 2017. Disponível em http://www.scielo.br/scielo.php?pid=S0104-71832017000100029\&script=sci abstract\&tIng=pt. ISSN 1806-9983. https://doi.org/10.1590/s0104-71832017000100002. Acesso em $31 / 01 / 2020$

ROHDEN, Fabíola. "'Os hormônios te salvam de tudo': produção de subjetividades e transformações corporais com o uso de recursos biomédicos". Mana [online], Rio de Janeiro, v. 24, p. 199-229, 2018a. Disponível em http://www.scielo.br/scielo.php?pid=S0104-93132018000100199\&script=sci abstract\&tlng=pt. ISSN 1678-4944. http://dx.doi.org/10.1590/1678-49442018v24n1p199. Acesso em 31/01/2020.

ROHDEN, Fabíola. "Considerações teórico-metodológicas sobre objetos instáveis e ausências presentes: analisando processos de materialização do desejo feminino". In: SEGATA, Jean; RIFIOTIS, Theophilos. Políticas etnográficas no campo da ciência e das tecnologias da vida. 1. ed. Porto Alegre: EDUFRGS, 2018b. p. 135-158.

SÁ, Ivone Manzali de. "'Fito-hormônios': ciência e natureza no tratamento do climatério". Physis [online], v. 22, n. 4, p. 1503-1522, 2012. Disponível em http://www.scielo.br/scielo. php?pid=S0103-73312012000400013\&script=sci_abstract\&tIng=pt. ISSN 0103-7331. https://doi. org/10.1590/S0103-73312012000400013. Acesso em 31/01/2020. 
SANTOS, Ananda Cerqueira Aleluia dos. "Adeus, hormônios!": concepções sobre corpo e contracepção na perspectiva de mulheres jovens. 2018. Dissertação (Mestrado) - Programa de Pós-Graduação em Saúde Pública, Universidade de São Paulo, São Paulo, São Paulo, Brasil.

ZANELLI, Carolina. "Percepção da Fertilidade: Parte 4 - O Método Sintotermal", In: ZANELLI, Carolina. Lado Oculto da Lua: uma outra visão sobre fertilidade feminina, 29 maio 2015a. Disponível em http://www.ladoocultodalua.com/2015/05/29/percepcao-da-fertilidade-parte-4-o-metodosintotermal/.

ZANELLI, Carolina. "Percepção da Fertilidade: Parte 3 - O Ciclo Menstrual". In: ZANELLI, Carolina. Lado Oculto da Lua: uma outra visão sobre fertilidade feminina, 08 maio 2015b. Disponível em http://www.ladoocultodalua.com/2015/05/08/ciclo-menstrual/.

Bruna KIöppel (brune.uc@gmail.com) é bacharel em Ciências Sociais pela Universidade Federal de Santa Catarina, mestre em Antropologia Social pelo Programa de Pós-Graduação em Antropologia Social da Universidade Federal do Rio Grande do Sul e, atualmente, doutoranda no mesmo Programa. Pesquisa na área de Gênero e Sexualidades, Estudos Feministas da Ciência e Antropologia da Ciência e Tecnologia.

Fabíola Rohden (fabiola.rohden@gmail.com) é mestre e doutora em Antropologia Social pela Universidade Federal do Rio de Janeiro (2000). Atualmente, é Professora Adjunta do Departamento de Antropologia da Universidade Federal do Rio Grande do Sul. Realiza pesquisas e assessorias nas áreas de relações de gênero, corpo, sexualidade, saúde, gênero e ciência e história da medicina no Brasil.

\section{COMO CITAR ESSE ARTIGO DE ACORDO COM AS NORMAS DA REVISTA}

KLÖPPEL, Bruna; ROHDEN, Fabíola. "Práticas de percepção da fertilidade entre mulheres jovens". Revista Estudos Feministas, Florianópolis, v. 29, n. 1, e61724, 2021.

\section{CONTRIBUIÇĀO DE AUTORIA}

Bruna Klöppel - Contribuiu com a concepção, a coleta e análise dos dados, a elaboração do manuscrito, a redação, a discussão dos resultados e a revisão.

Fabíola Rohden - Contribuiu com a concepção, a elaboração do manuscrito, a redação, a discussão dos resultados e com a revisão.

A versão original deste artigo foi traduzida para o inglês por Jeffrey Hoff (jeffhoff@floripa.com.br).

\section{FINANCIAMENTO}

O presente trabalho foi realizado com apoio da Coordenação de Aperfeiçoamento de Pessoal de Nível Superior - Brasil (CAPES) - Código de Financiamento 001, e do Conselho Nacional de Desenvolvimento Científico e Tecnológico (CNPq).

\section{CONSENTIMENTO DE USO DE IMAGEM}

Não se aplica.

\section{APROVAÇĀO DE COMITÊ DE ÉTICA EM PESQUISA}

Não se aplica.

\section{CONFLITO DE INTERESSES}

Não se aplica

\section{LICENÇA DE USO}

Este artigo está licenciado sob a Licença Creative Commons CC-BY 4.0 International. Com essa licença você pode compartilhar, adaptar, criar para qualquer fim, desde que atribua a autoria da obra.

\section{HISTÓRICO}

Recebido em 25/02/2019

Reapresentado em 14/02/2020

Aprovado em 09/06/2020 